\title{
TAXON-SPECIFIC TEMPORAL SHIFTS IN POLLINATING INSECTS IN MASS- FLOWERING CROPS AND FIELD MARGINS IN IRELAND
}

\author{
Irene Bottero*, Simon Hodge, Jane C. Stout \\ Department of Botany, School of Natural Sciences, Trinity College Dublin, Dublin, Republic of Ireland
}

Journal of Pollination Ecology, 28(8), 2021, pp 90-107

DOI: $10.26786 / 1920-$

$7603(2021) 628$

Received 28 September 2020, accepted 21 March 2021

*Corresponding author: botteroi@tcd.ie

\begin{abstract}
In intensively cropped agricultural landscapes, the vegetation in edges and hedges (henceforth "field margins") represents an important semi-natural habitat providing fundamental resources for insect pollinators. We surveyed the pollinating insects associated with two mass-flowering crops, apple and oilseed rape, and compared the insect fauna of the main crop with that in the field margins in the grass-dominated agricultural landscapes of Ireland. Different insect groups responded differently to the presence of the flowering crop, with honey and bumble bees more abundant in crops than margins during crop flowering, but more hover flies and butterflies in margins throughout. The composition of the insect assemblage also shifted over time due to taxon-specific changes in abundance. For example, solitary bees were most abundant early in the season, whereas hover flies peaked, and butterflies declined, in mid-summer. The temporal shift in insect community structure was associated with parallel changes in the field margin flora, and, although we found no relationship between insect abundance and abundance of field margin flowers, Bombus abundance and total insect abundance were positively correlated with floral diversity. After the crop flowering period, floral abundance and diversity was maintained via margin plants, but by late summer, floral resources declined. Our results confirm the importance of field margins for insect pollinators of entomophilous crops set within grass-dominated landscapes, even during the crop flowering period, and provide additional support for agrienvironment schemes that protect and/or improve field margin biodiversity. The results also demonstrate that although shifts in insect and plant communities may be linked phenologically there may not always be simple relationships between insect and floral abundance and richness.
\end{abstract}

Keywords—Apis mellifera, Bombus spp., hover flies, butterflies, Ireland, phenology

\section{INTRODUCTION}

Flower-visiting insects such as honey bees, bumble bees, solitary bees, hover flies and butterflies provide an ecosystem service by pollinating a wide range of wild and cultivated plants (Ollerton et al. 2011). Many of these insects are declining due to a combination of threats arising from habitat loss, pesticide exposure, invasive species and climate change (IPBES 2016). Habitat disturbance (fragmentation, degradation and habitat loss) is one of the main stressors negatively impacting insect communities (Goulson et al. 2008; Winfree et al. 2009; Le Féon et al. 2010; Kovács-Hostyánszki et al. 2011; Scheper et al. 2013; Hass et al. 2018), with associated losses of floral resources subsequently leading to disruption of plant-pollinator interaction networks (Day 1991; O' Toole 1994; Gathmann \& Tscharntke 2002).

Shifts in land use from semi-natural habitat to intensive agriculture have been associated with greatly reduced biodiversity, including pollinating insects, in many regions of the world (Ghazoul 2005; Goulson et al. 2008). In degraded agricultural landscapes, outside of the flowering period of mass-flowering crops, both managed and naturally-occurring pollinating insects can face 'hunger gaps' when the quantity and quality of pollen and nectar available does not meet requirements (Timberlake et al. 2019). In this scenario, hedgerows and naturally-occurring wild 
flowering species in field margins represent an important food resource for many insect species (Stanley \& Stout 2014), and positive relationships between farmland pollinating insects and the diversity of floral resources in these habitats are often demonstrated (e.g. Papanikolaou et al. 2017). In addition, hedgerows and field edges (i.e. the space beyond the edge of the crop, and the physical boundary, be that a wall, hedgerow or fence; henceforth "field margins") provide shelter, larval host plants, a source of prey, and relatively high floral diversity compared with that occurring in the centre of the main crop, and so are important for supporting biodiversity in agricultural landscapes (Wratten 1988; Marshall \& Moonen 2002). Because of their natural seasonal flowering sequence, the plants in field margins provide resources at different times of the year, at different stages of the pollinator life cycle, and/ or the development of the colony (Rotenberry 1990; Marshall \& Moonen 2002; Cole et al. 2017). Additionally, the interactions between managed and wild pollinators will, inevitably, change in space and time in relation to both the phenologies of the mass-flowering crop and that of the wild plant species present in the same foraging ranges.

Deliberate introduction of native plant species into field margins, augmentation of flora by sowing seed mixes or the creation of floral 'strips', are common techniques used in agri-environment schemes to increase numbers and diversity of pollinators and other beneficial insects (e.g. Haaland et al. 2011; Campbell et al. 2017; Curtis et al. 2019; Heller et al. 2019). The value of these planting schemes to pollinating insects, however, can be highly variable and taxonomically biased (Campbell et al. 2017; Wix et al. 2019), and their overall effectiveness can be dependent upon the landscape context and the type of farming under consideration (e.g. cropland vs grassland) (Scheper et al. 2013). In general, studies have focussed on the role of field margins for pollinators in cropdominated landscapes, and in grasslands of "high biological value" - e.g. wet, calcareous or alpine grasslands (Marshall \& Moonen 2002; Plantureux et al. 2005). Relatively few studies have examined the role of field margins in shaping insect communities in agricultural landscapes dominated by intensive grasslands (but see Power \& Stout 2011; Stanley \& Stout 2013).
In the Republic of Ireland, more than $60 \%$ of total land area is managed as agricultural land, and $80 \%$ of this land is considered as "improved" (i.e. intensively managed) agricultural grassland for livestock production and dairy, with a smaller area used for arable-based crop and horticultural production (The Heritage Council, 2010; Marshall \& Moonen 2002; Sheridan et al. 2011; Scheper et al. 2013). These landscapes are characterised by highly modified monoculture grasslands and ryegrass leys, subjected to intensive management, such as reseeding, fertilisation, grazing and silage making (Fossitt 2000). Field margin structures such as hedgerows are a consistent feature in Irish farmland, and in a landscape dominated by species-poor improved grasslands, often provide a large portion of the semi-natural habitat available for wild pollinators and other wild animals. Larkin et al. (2019), in a study of 119 intensively managed farms, reported that hedgerows were present in $100 \%$ of arable, beef and dairy farms and comprised almost $3 \%$ of their areas.

Flowering crops are rare in Irish landscapes but include oilseed rape (OSR; $\approx 10,000$ ha grown in Ireland), other brassicas used for animal fodder, and apples for both direct consumption and cider making ( $\approx 700$ ha; fao.org/faostat 2018 data). As mass-flowering entomophilous crops, both apples and OSR produce large amounts of pollen and nectar that attract a range of flower-visiting insects, and are especially useful for insects such as bees when high quantities of resources are required early in the season for nest establishment and, in social species, colony growth. In terms of pollination services, apple growers often augment natural pollinator populations by installing commercially produced bumble bee colonies and/ or have honey bee apiaries onsite. Oilseed rape is not obligately dependent on bees or other insects for pollination, but beekeepers often site apiaries on or near OSR fields, and studies have shown that seed set and total yield can be significantly reduced if insect pollinators are excluded (Stanley et al. 2013; Perrot et al. 2018).

Thus, overall, communities of pollinating insects in field margins will be influenced by multiple factors, including landscape context, crop type and management, the diversity and abundance of flower resources present in the field margin and seasonality with regards to crop mass- 
flowering. This study used both an annual (OSR) and a perennial (apple) early-season, massflowering crop, within a grass-dominated agricultural landscape, to: (1) compare the abundance of major pollinating insect groups within the centre of the main flowering crop with their abundance in the field margins, (2) investigate whether and how the composition of the pollinator assemblage shifted in time, in connection with the changes that occur during and after the blossoming period of the mass-flowering crops, and (3) identify any relationships between insect abundance and diversity with the abundance and diversity of wild flowering plants occurring in field margins.

\section{MATERIALS AND METHODS}

\section{STUDY SITES}

The investigation was conducted between April and August 2019 at eleven study sites in The Republic of Ireland. Six sites consisted of fields of winter-sown OSR to represent an annual massflowering crop, and five sites were apple orchards that represented a perennial flowering crop (Fig. 1; Appendix I). Study sites ranged in size from 0.4 ha to $22 \mathrm{ha}$ and were a minimum distance of $9 \mathrm{~km}$ apart. The area of grassland in the landscape which surrounded the sites (1 $\mathrm{km}$ radius) ranged approximately from $15 \%$ to $74 \%$, with a mean of almost $40 \%$ (Appendix I). All sites had honey bee hives $(\geq 3)$ and commercial colonies of Bombus terrestris $(\geq 3)$ along some field boundary or in close proximity.

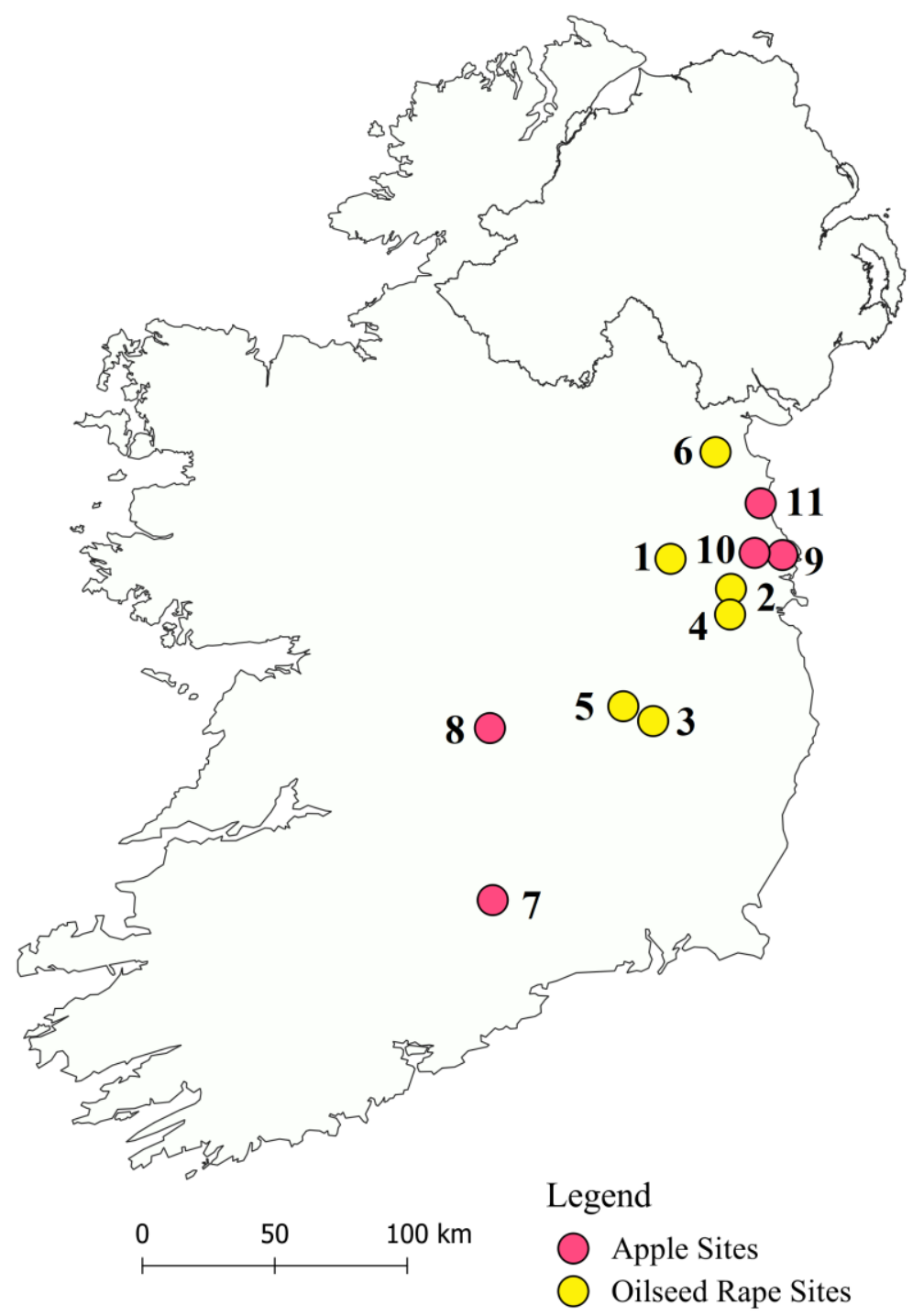

FIGURE 1. Location of study sites. Numbers correspond with descriptions in Appendix I. Image created with QGIS software. 


\section{INSECT SURVEYS}

The aims of the insect pollinator surveys were twofold: (1) to compare the communities of insects within the centre of the target crops with their associated field margins during the crop flowering period, and (2) to examine how the field margin insect communities changed over time relative to the flowering period of the main crop.Each survey consisted of walking a $100 \mathrm{~m}$ transect over a 10minute period and recording the flower-visiting insects $1 \mathrm{~m}$ either side of the observer (total area $200 \mathrm{~m}^{2}$ ), both those actually visiting flowers, and those flying/resting in the transect area. Effort was made to avoid re-counting the same individuals during the course of the surveys but, since individuals were not captured, it is possible that some individuals were counted more than once. All surveys were performed between 9 am and 6 pm and were conducted during suitable weather conditions for insect activity (wind speed $<6 \mathrm{~m} / \mathrm{s}$; temperature $10-28^{\circ} \mathrm{C}$; no rain).

For quantitative analysis, insects were assigned to one of five groups: Apis mellifera, Bombus spp, solitary bees, hover flies, or butterflies. We chose to use these five pollinator taxa because they are well recognized, sub-divisions of the of pollinating insects, and we feel information at this level provides a suitable description of the coarse structure of the functional guild. We did not perform any lethal sampling which meant that we could not identify hoverflies and solitary bees to species with confidence. Nevertheless, to gain some insight into which species were found in the study sites, the more abundant butterflies and Bombus were also identified to species level, with cryptic Bombus species grouped under the label of Bombus terrestris/lucorum agg. (Carolan et al. 2012).

As a measure of insect richness, the number of insect groups (from five) present in each site visit was recorded. The counts of each of the five groups were then used to produce a version of the Shannon-Wiener diversity index, where diversity $(H)=-\Sigma p_{\mathrm{i}} \cdot \ln \left(p_{\mathrm{i}}\right)$ and $p_{\mathrm{i}}$ is the proportion of individuals making up the $i$ th insect group.

The pollinator surveys were performed during three different periods (Appendix I):

1. During the crop flowering period (April-May 2019)
2. Approximately one to two months after the crop flowering period (June-July 2019)

3. Approximately three months after the crop flowering period (August 2019)

In Period 1, during crop flowering, each site was visited on two occasions. On each visit, two 10-minute insect surveys were performed in the centre of the crop, and then a mean of the counts for each insect group obtained. The two transects were chosen to be at least $30 \mathrm{~m}$ apart. The samplings were performed close to the crop centre or, when the crops/orchards were too wide, at least $30 \mathrm{~m}$ from the edge of the crop. Similarly, two 10 minute surveys were performed in the field margins (one survey on each of two randomly chosen field boundaries) and a mean of these counts was obtained.

To examine the change in field margin insect communities over time, each site was visited on two occasions in Periods 2 and 3. At all 11 sites, one 10-minute field margin survey was performed on each of two randomly chosen field boundaries on each visit. For each site, the pollinator counts on each sampling visit were performed on the same two margins that were randomly chosen during Period 1. Additionally, at the apple sites, two 10minute insect surveys were also performed in the centre of the crop. No surveys were performed in Periods 2 and 3 in the centre of OSR crops because of limited access to the fields due to normal farming operations.

\section{SURVEY OF FLOWERING PLANTS}

The aim of the floral surveys was to collect information concerning the relative abundance and diversity of floral resources in addition to the main crop during the different periods of the study. One floral survey was conducted at each site in each study period.

In each survey, the field margin flora was assessed at 12 locations, located at approximately $25 \%, 50 \%$ and $75 \%$ of the length of the four main field boundaries. GPS coordinates of each location were recorded so approximately the same locations could be used in each study period. Using a $1 \times 1 \mathrm{~m}$ quadrat to give a standardized sample area, at each location, the entomophilous plant species that were in flower were recorded on the ground and also in a vertical plane at a height of $1.5 \mathrm{~m}$ if the boundary was surrounded by a 
hedge, wall or fence. In each quadrat, the total number of floral units (Dicks et al. 2002; Baldock et al. 2015) present was assigned to four categories: 0 $\equiv$ no flowers present; $1 \equiv 1$-10 floral units; $2 \equiv 11-100$ floral units; $3 \equiv>100$ floral units.

To produce a summary measure of floral abundance on each site visit, the median of the 12 scores was calculated. As a measure of floral diversity, the number of flowering species present in the 12 samples, on each site visit, was recorded. Additionally, we thought it desirable to include a diversity index in addition to floral species richness to provide additional information on the evenness (or dominance) of the flowering plants present at each site. Rather than abundance of floral units, we have used the presence of each plant species in each of the 12 quadrats to reflect their frequency in the overall assemblage. We then used a version of the Shannon-Wiener diversity index calculated as, $H=-\Sigma f_{i} \cdot \ln \left(f_{i}\right)$, where $f_{i}$ is the frequency of the $i$ th species in terms of the proportion of sampling locations (from 12) where it was recorded.

\section{DATA ANALYSIS}

Statistical analyses were performed using Genstat v19 software (VSN International Ltd UK) and Community Analysis Package v4 (Pisces Conservation Ltd., UK).

During the crop flowering period, to compare the insects present in the crop centre with those found in the field margins, account had to be taken of the non-independence of comparisons made within each site, and on each sampling visit. Therefore, a residual maximum likelihood ( $R E M L)$ mixed model was fitted with crop type (APP or OSR) and location (crop centre or field boundary) defined as fixed factors and site and sampling visit as random factors. To compare the insect assemblages in the centre and field margins of the apple crops over the three sampling periods, a REML repeated-measures model was fitted with location (crop centre or field margin) and sample period treated as fixed factors and site and sitevisit as random factors.

For the analysis of the field margin insect and floral data (abundance, species richness and diversity) over time in both crops, a REML repeated-measures model was fitted with crop type (APP or OSR) and sample period fitted as fixed factors and site as a random factor. For this analysis, a mean of the insect counts from all four surveys over the two visits for each site was obtained, resulting in one value per site per period for each pollinator group. This procedure simplified the repeated measures analysis, and resulted in an insect taxon-by-sample matrix with the same structure as that of the floral taxon-bysample matrix, which subsequently allowed the comparison of insect and floral similarity matrices using a Mantel test (as described below). In the above REML analyses, insect counts were square root transformed prior to analysis, to lessen the effects of extreme counts and increase normality of error terms. Insect taxonomic richness and diversity and all three of the floral response variables were not transformed.

Examination of the relationships between field margin insect abundance and diversity with floral abundance and diversity were assessed by Spearman's rank correlation using the summary data from the 33 site visits.

To examine the composition of the field margin insect and floral assemblages present in each crop in each period, non-metric multidimensional scaling (NMDS) was performed based on BrayCurtis similarity matrices. For the analysis of floral data, the frequency of each species, from 12 positions around the field boundary, was used as a measure of relative abundance. For the insects, the square root of the mean counts for each taxon at each site in each time period were used in the analysis. Separation of samples based on crop and sampling period was assessed using analysis of similarity (ANOSIM; Clarke 1993; Henderson \& Seaby 2008), which produces an indication of statistical significance by comparing the relative within- and between-group similarity with that obtained by 1000 random permutations of the raw data.

A Mantel test, based on the similarity matrices used for the NMDS, was used to examine the association between the shifts in the plant and field margin insect assemblages over time and between crop types. This test used Spearman's rank correlation to give a base indication of the strength of the relationship and obtained a $P$-value by calculating the proportion of 1000 random permutations of the similarity matrices which produced a higher correlation coefficient. The 
whole process was performed 20 times and a mean $P$-value obtained.

\section{RESULTS}

A total of 3,048 insect was recorded during the 216 ten-minute surveys (36 hours of observation) carried out during the whole study, consisting of 1,052 Apis mellifera, 618 Bombus spp., 167 butterflies, 1,013 hover flies and 198 solitary bees.

In the 88 ten-minute surveys (total 14.67 hours of observations) carried out during the main crop flowering period, a total of 1,543 pollinating insects were observed, consisting of 900 Apis mellifera, 264 Bombus spp., 150 solitary bees, 174 syrphids and 55 butterflies. There were no overall statistically significant differences between the apple and OSR crops in terms of insect diversity or the abundance of any of the five insect groups, although there was moderate evidence $(P=0.055)$ that solitary bees were more abundant in apples than OSR (Tab. 1A; Fig. 2).

Apis mellifera and solitary bees showed no significant differences in abundance between the crop centre and the field margins (Tab. 1A; Fig. 2), whereas butterflies and syrphids were more abundant in the field margins than in the crop centre, especially in OSR. Bombus were more abundant in the crop centre than in the field margins, although this effect was only apparent in the apple orchards (Fig. 2, Appendix II). The most abundant butterfly species recorded were Anthocaris cardamine and Pieris spp. (Appendix II). Five species of Bombus were recorded: B. hortorum, B. pascuorum, B. pratorum, B. lapidarius and individuals belonging to the $B$. terrestris/lucorum aggregation (Appendix II).

Table 1. Results of REML analysis (P-values) examining the response of insect abundance and pollinator diversity to: (A) crop type (APP v OSR) and location (crop centre v field margin) during the main crop flowering period (B) location (crop centre $v$ field margin) and study period considering only the insects recorded in the apple sites and (C) crop type (APP $v$ OSR) and study period considering the insects in both crops but only in the field margins. Insect abundance data were square root transformed before analysis. n.d.f. - numerator degrees of freedom.
(A)

\begin{tabular}{llll}
\hline & Crop type & Location & Interaction \\
n.d.f. & 1 & 1 & 1 \\
\hline Apis mellifera & 0.609 & 0.098 & 0.217 \\
Bombus & 0.588 & $\mathbf{0 . 0 2 9}$ & $\mathbf{0 . 0 1 4}$ \\
Butterflies & 0.756 & $\mathbf{0 . 0 3 2}$ & 0.158 \\
Solitary bees & 0.055 & 0.390 & 0.470 \\
Syrphids & 0.380 & $\mathbf{0 . 0 2 7}$ & 0.731 \\
Total & 0.709 & 0.462 & $\mathbf{0 . 0 3 3}$ \\
& & & \\
Richness & 0.348 & 0.063 & 0.859 \\
Diversity & 0.156 & 0.203 & 0.733 \\
\hline
\end{tabular}

(B)

\begin{tabular}{llll}
\hline & Period & Location & Interaction \\
n.d.f. & 2 & 1 & 2 \\
\hline Apis mellifera & $\mathbf{0 . 0 4 1}$ & 0.639 & $\mathbf{0 . 0 0 3}$ \\
Bombus & 0.548 & 0.206 & $\mathbf{0 . 0 1 7}$ \\
Butterflies & $\mathbf{0 . 0 0 3}$ & $\mathbf{0 . 0 1 2}$ & 0.102 \\
Solitary bees & $\mathbf{0 . 0 1 5}$ & 0.213 & 0.409 \\
Syrphids & $\mathbf{0 . 0 4 7}$ & $<\mathbf{0 . 0 0 1}$ & 0.316 \\
Total & 0.201 & 0.326 & 0.002 \\
& & & \\
Richness & 0.149 & $<\mathbf{0 . 0 0 1}$ & 0.206 \\
Diversity & $\mathbf{0 . 0 2 4}$ & $<\mathbf{0 . 0 0 1}$ & 0.247 \\
\hline
\end{tabular}

(c)

\begin{tabular}{llll}
\hline & Crop type & Period & Interaction \\
n.d.f. & 1 & 2 & 2 \\
\hline Apis mellifera & 0.766 & 0.082 & 0.512 \\
Bombus & 0.106 & 0.430 & 0.466 \\
Butterflies & 0.245 & $<0.001$ & 0.591 \\
Solitary bees & 0.445 & $\mathbf{0 . 0 1 6}$ & 0.124 \\
Syrphids & 0.118 & $\mathbf{0 . 0 0 4}$ & 0.524 \\
Total & 0.180 & 0.181 & 0.936 \\
& & & \\
Richness & 0.577 & 0.160 & 0.718 \\
Diversity & 0.669 & 0.092 & 0.845 \\
\hline
\end{tabular}



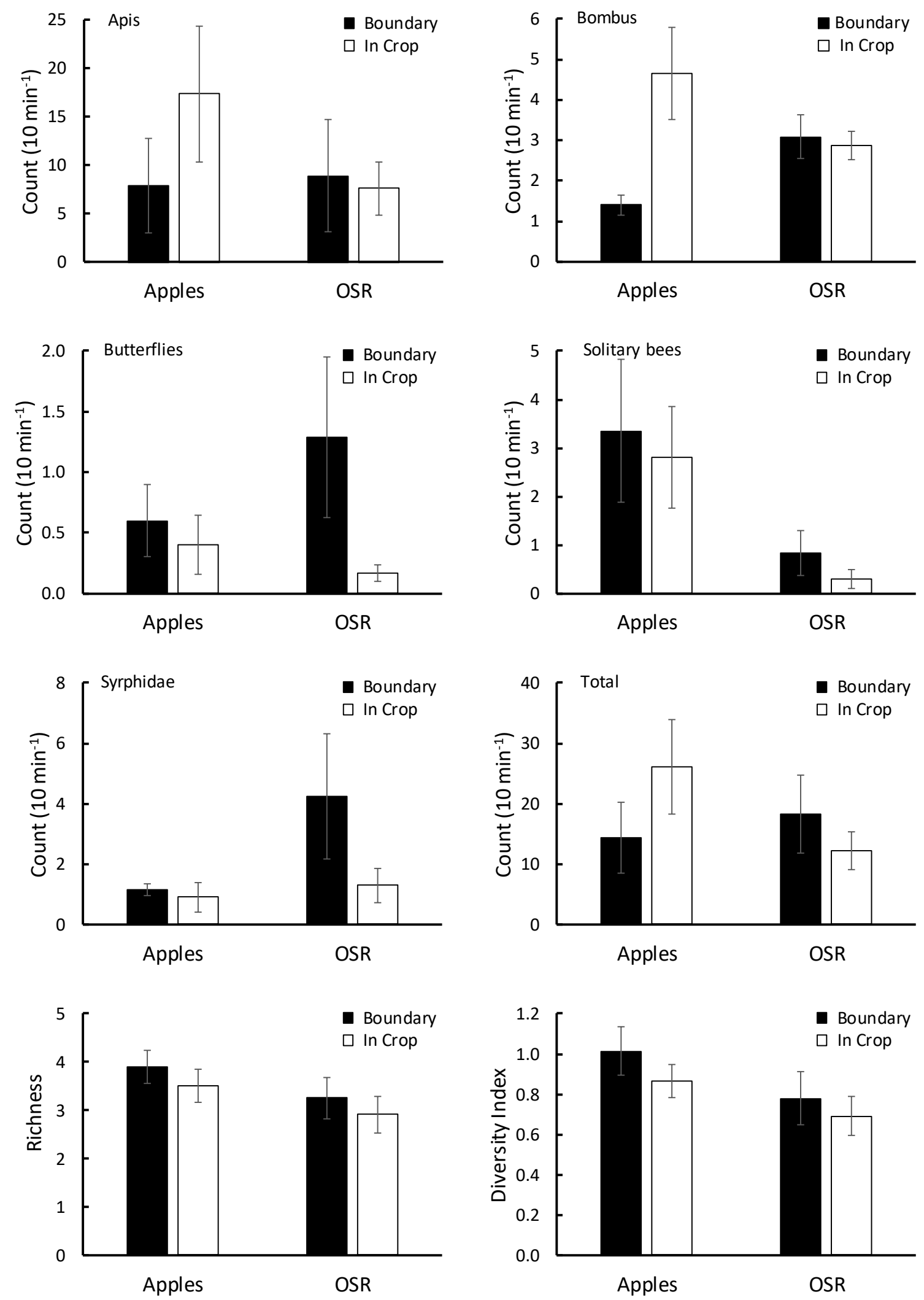

Figure 2. Abundance and diversity (mean $\pm \mathrm{SE}$ ) of pollinating insects in the centre of the main crop and in the field margins during flowering of OSR $(n=6)$ and apples $(n=5)$. 
INSECTS IN THE CENTRE AND FIELD MARGINS OF APPLE ORCHARDS DURING AND AFTER MAIN CROP FLOWERING

In the 120 ten-minutes surveys (total 20 hours of observations) performed in the apple orchards, a total of 1,488 pollinating insects were recorded, consisting of 595 Apis mellifera, 302 Bombus spp., 134 solitary bees, 394 syrphids and 63 butterflies. Eleven species of butterflies and six species of bumble bees were observed during the surveys, the most abundant being Pieris spp. and $B$. terrestris/lucorum agg. respectively (Appendix II).

Overall, there was steady decline in insect numbers over the three observation periods, with 810 insects observed in Period 1 (during apple flowering), 437 in Period 2 and 241 in Period 3 (Tab. 1B; Fig. 3).

Apis mellifera, Bombus spp. and solitary bees were most abundant during the main crop flowering period. Additionally, Apis mellifera and Bombus spp. were most abundant in the centre of the crop during this first period (Tab. 1B; Fig. 3). Bombus were evenly distributed between the centre and field margins in Periods $2 \& 3$, whereas Apis mellifera, although very much reduced in numbers, were more common in the field margins than the centre of the orchard.

Solitary bees showed no overall differences in abundance between the field centre and margins, and were very uncommon later in the season (Tab. 1B; Fig. 3). Butterflies and syrphids were both most abundant in the field margins compared with the centre of the crop, but whereas butterflies showed a dip in abundance in Period 2, there was a peak in hover fly observations in the same period (Tab. 1B; Appendix II; Fig. 3; see also Fig. 4).

INSECTS IN THE FIELD MARGINS OF BOTH CROPS DURING AND AFTER THE MAIN CROP FLOWERING PERIOD

In the 132 ten-minute surveys (total 22 hours of observations) carried out during the three study periods in the field margins, a total of 2,015 pollinating insects were recorded, consisting of 522 Apis mellifera, 367 Bombus spp., 136 solitary bees, 848 syrphids and 142 butterflies. Sixteen species of butterfly, which represents just under half of the 33 species currently listed as resident in Ireland, and six species of Bombus recorded along the field margins over the three periods, with Bombus terrestris/lucorum agg. making up around $60 \%$ of the Bombus records (Appendix II).

No significant differences occurred between the apple and OSR crops in terms of abundance of any insect group and the diversity measures, and there were no significant statistical interactions between crop type and survey period (Tab. 1C; Fig. 4).

FLOWERING PLANTS IN THE FIELD MARGINS DURING AND AFTER THE MAIN CROP FLOWERING PERIOD

Across the 33 site visits, 82 species of plants were observed in flower in the field margins; 73 species on the ground and 25 species in the 'vertical' hedge quadrats. Many plant species were relatively uncommon over the whole study period, and 41 of the 82 species recorded were only observed in one of the 33 surveys. Common species (> $30 \%$ of site visits) included Rubus fruticosa, Ranunculus repens, Crataegus monogyna and Vicia sepium (Appendix III). The two most common flowering woody species flower in sequence (C. monogyna in May-June, and $R$. fruticosus June-August), whereas the two most common herbaceous species (Ranunculus repens and Vicia sepium) were in flower in all sampling periods.

There were no statistically significant differences between the apple and the OSR sites in terms of the field margin floral abundance and diversity measures (Tab. 2; Fig. 5), although abundance and diversity of field margin flowers did differ significantly among the three periods, the patterns being slightly different in the two crops, but in general these values were lowest in Period 3 (Tab. 2; Fig. 5).

NMDS ANALYSIS OF INSECTS AND FLOWERING PLANTS IN THE FIELD MARGIN

For the assemblages of pollinating insects, the NMDS analysis did not distinguish the samples from the different crops in any study period (ANOSIM, $P>0.20$ ) but did separate the assemblages recorded in the three different sampling periods into more-or-less distinct clusters (ANOSIM $P<0.002$; Fig. 6). The Period 1 data were separated from that obtained in Periods 2 and 3 along NMDS Axis 1, whereas the Period 3 samples were separated from the Period 1 and 2 samples along NMDS Axis 2 (Fig. 6). Relative to Period 1, the Period 2 samples were associated with a high abundance of syrphids, whereas 

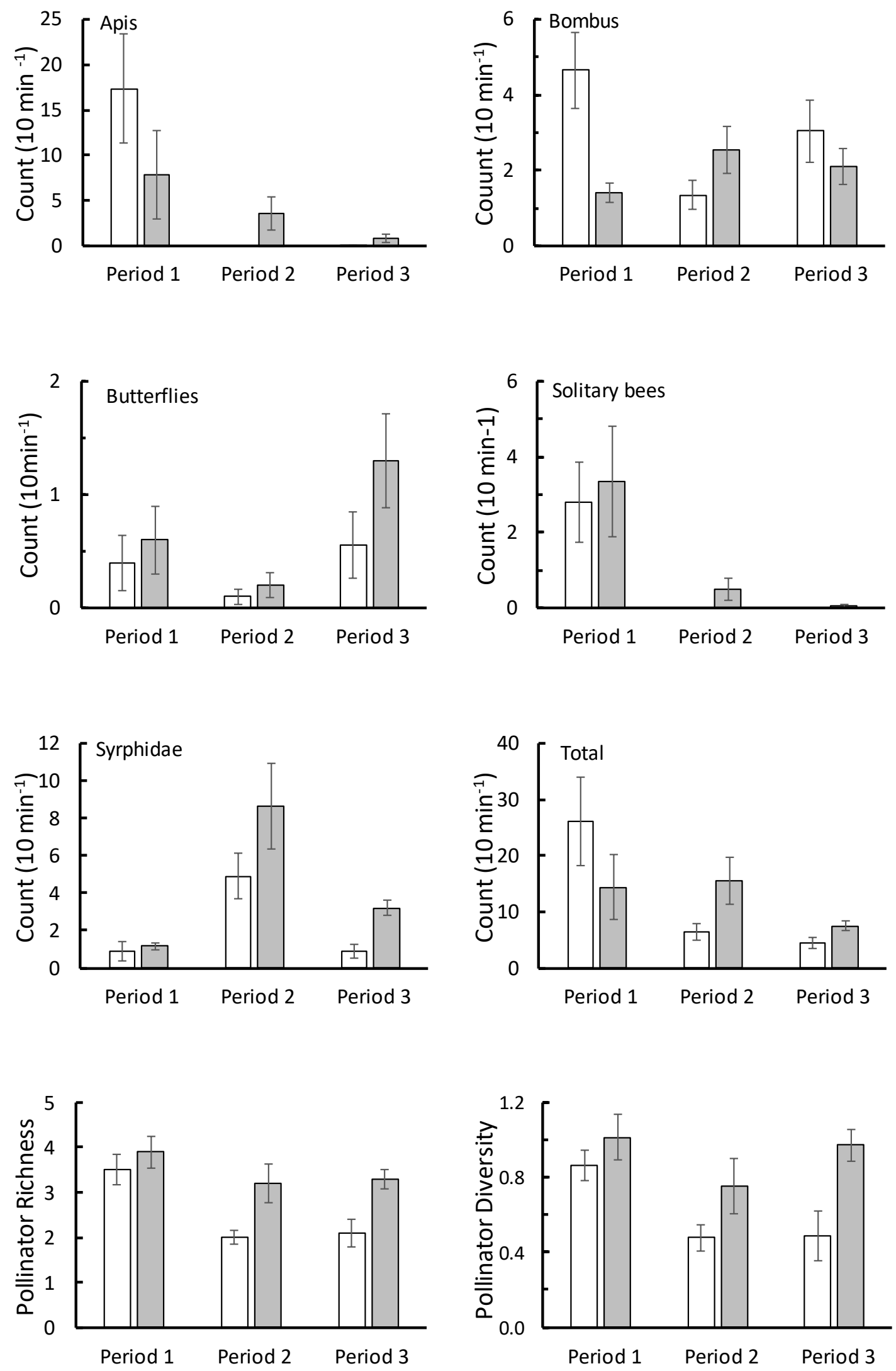

Figure 3. Abundance (mean $\pm \mathrm{SE}$ ) and diversity of pollinating insects in the centre of the crop (white columns) and field margins (grey columns) of apple orchards $(n=5)$ during (Period 1), 1-month after (Period 2) and 3-months after flowering (Period 3) of the main crop. 

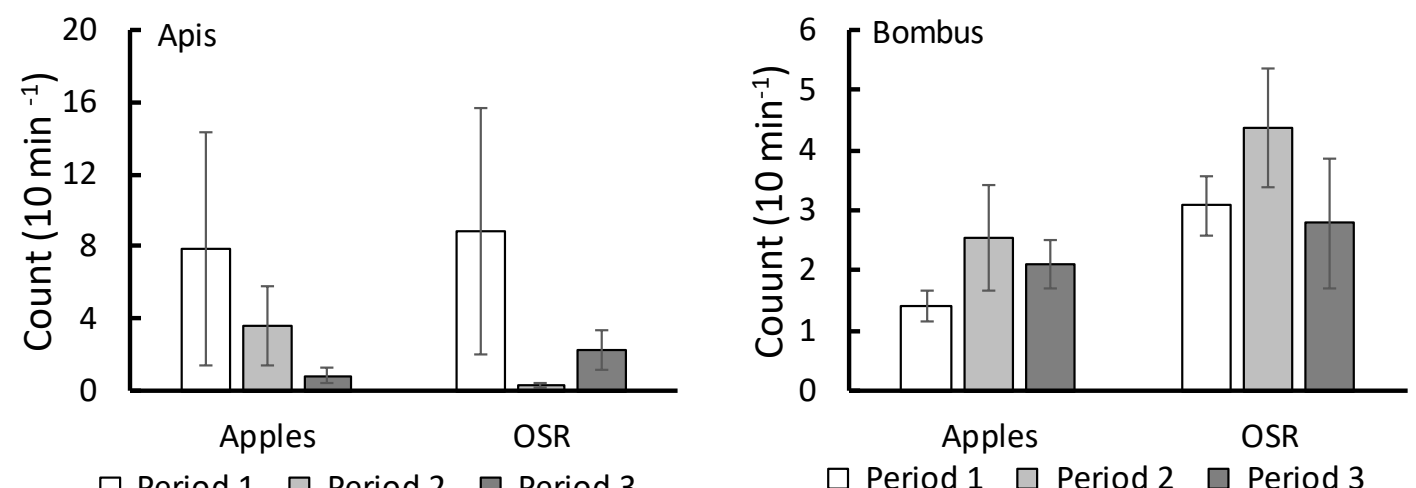

$\square$ Period $1 \quad \square$ Period $2 \quad \square$ Period 3

$\square$ Period $1 \square$ Period $2 \square$ Period 3
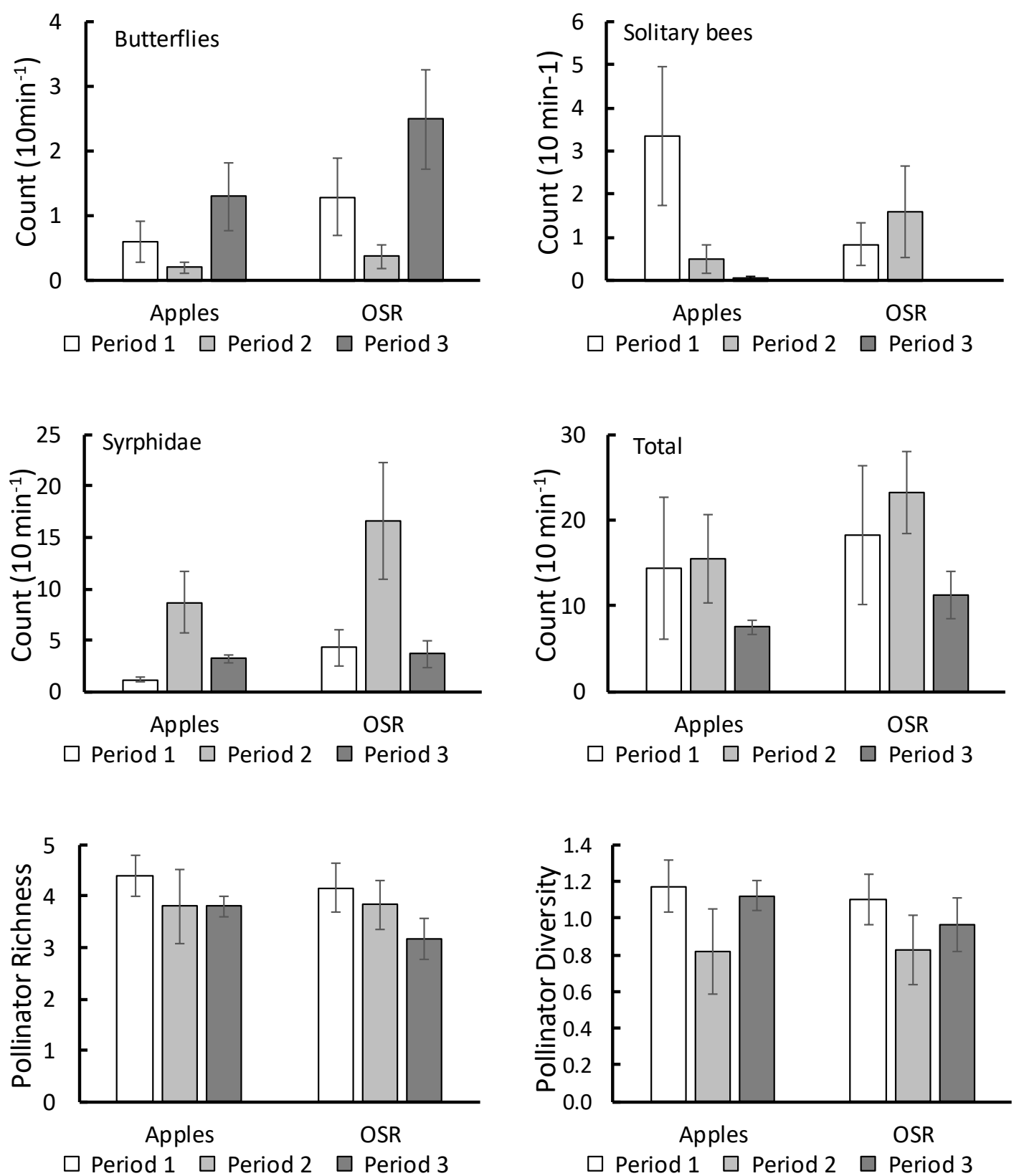

Figure 4. Abundance (mean $\pm \mathrm{SE}$ ) of pollinating insects in field margins during the flowering period (Period 1), 1-month after flowering (Period 2) and 3-months after flowering (Period 3 ) in OSR $(n=6)$ and apples $(n=5)$. 
Period 3 was associated with low numbers of solitary bees and high numbers of butterflies (see also Fig. 4).

The ANOSIM procedure indicated significant differences among the floral assemblages obtained in the different periods $(P<0.005)$ and, accordingly, the NMDS analysis indicated that the field margin flora observed in Period 1 was separated from those obtained in Periods 2 and 3 along NMDS Axis 1, and that Periods 2 and 3 were separated along Axis 2 (Fig. 6). The only groups of samples not identified as significantly different were the OSR and apples clusters in Period $2(P=$ $0.139)$, and the apple and OSR clusters in Period 3 $(P=0.115)$. From the NMDS plot, this result is visualized as a separation of the floral assemblages in OSR and apple crops in Period 1, but a convergence of the field margin floras in the two crops in the latter periods (Fig. 6). The Period 1 samples were associated with relatively high abundances of Crataegus monogyna and Taraxacum officinale (L.) Weber ex F.H. Wigg whereas the Period 2 and 3 surveys performed later in the year were associated with Rubus fruticosus and Geranium robertianum L. (Appendix III).

Table 2. Results of REML repeated measures analysis ( $P$-values) examining the effects of crop type (apples/ OSR) and period (flowering period/ 1-month after flowering period / 3-month after flowering period) on abundance and diversity of flowering plants in the field boundary. Site was included in the REML model as a random factor. n.d.f. - numerator degrees of freedom; d.d.f - denominator degrees of freedom.

\begin{tabular}{lccc}
\hline & Crop type & Period & Interaction \\
n.d.f. & 1 & 2 & 2 \\
d.d.f. & 9 & 18 & 18 \\
\hline $\begin{array}{l}\text { Median } \\
\text { abundance }\end{array}$ & 0.137 & $\mathbf{0 . 0 0 2}$ & 0.272 \\
$\begin{array}{l}\text { Total } \\
\text { species } \\
\text { richness }\end{array}$ & 0.610 & $\mathbf{0 . 0 0 4}$ & 0.373 \\
\begin{tabular}{l} 
Diversity \\
\hline
\end{tabular} & 0.414 & $<0.001$ & 0.068 \\
\hline
\end{tabular}
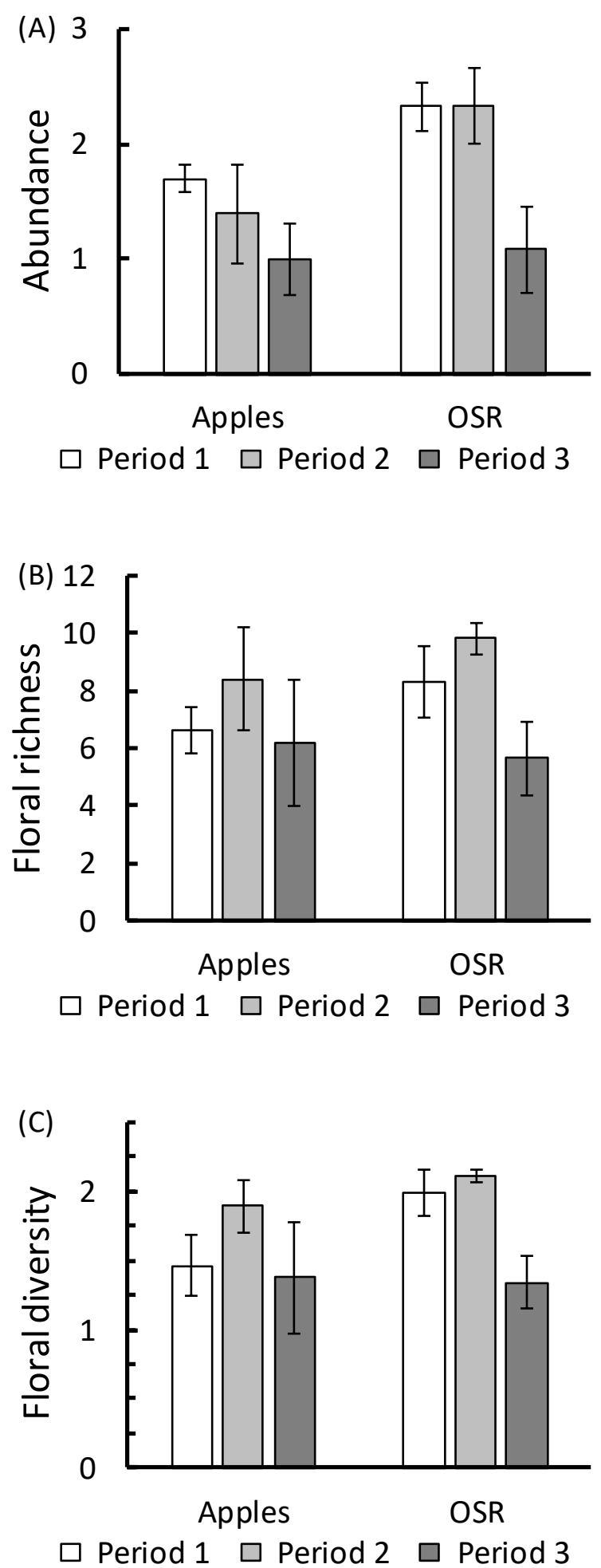

Figure 5. Abundance and diversity (mean $\pm \mathrm{SE}$ ) of entomophilous flowering plants in field boundaries during the flowering period (Period 1), 1-month after flowering (Period 2) and 3-months after flowering (Period 3) in OSR $(n=6)$ and apples $(n=5)$, where $(a)$ median abundance score, $(b)$ total species of species in flower, and (c) species diversity of flowering species. 


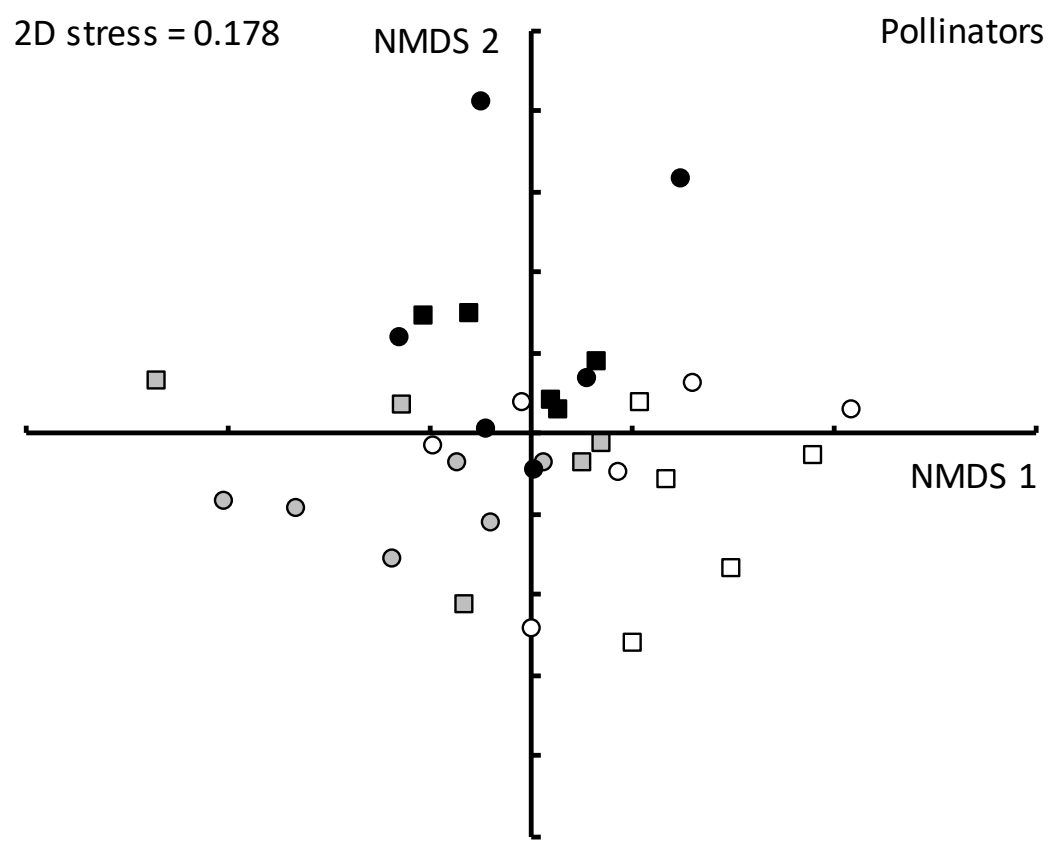

O OSR $1 \square$ APP 1 O OSR $2 \square$ APP $2 \bullet$ OSR $3 \bullet A P P 3$

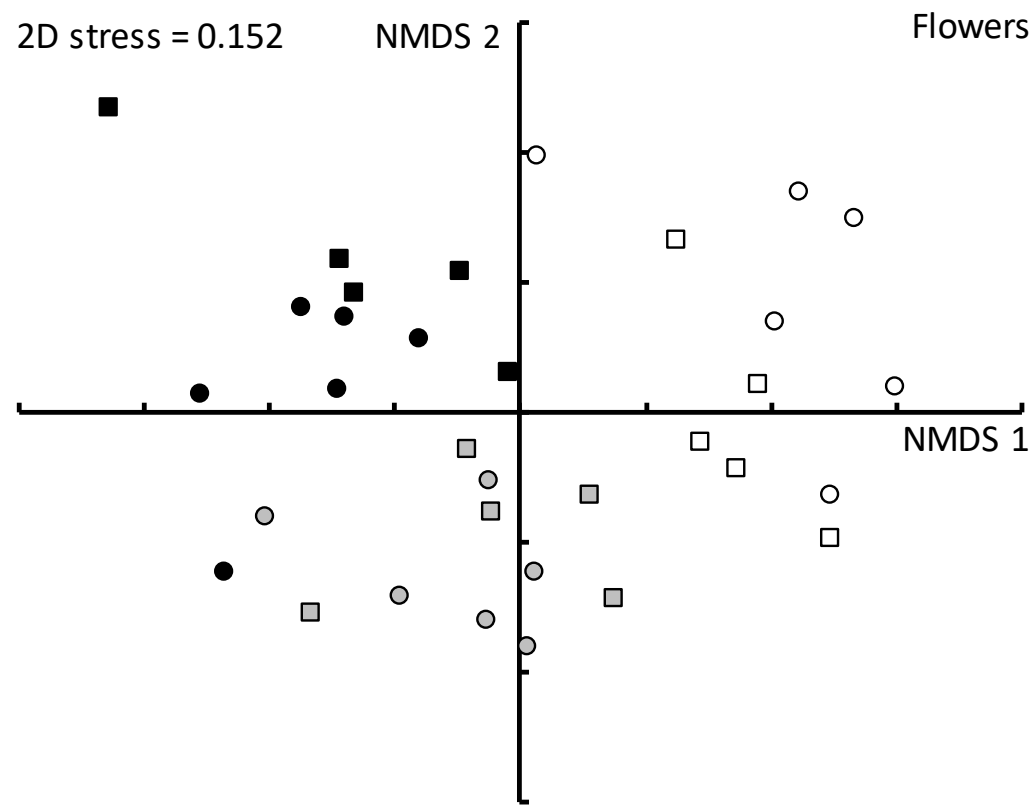

FIGURE 6. NMDS plots based on abundance of five groups of pollinating insects occurring in field margins and relative frequency of field boundary flowering plants in apple orchards (APP) and OSR during the main crop flowering (Period), 1-month after flowering (Period 2) and 3 O OSR $1 \square$ APP 1 O OSR $2 \square$ APP $2 \bullet$ OSR $3 \square$ APP 3 months after flowering (Period 3).

\section{RELATIONSHIPS BETWEEN INSECTS AND FLORAL ASSEMBLAGES}

Only weak to moderate correlations $(r S<|0.4|)$ were found between the abundance and diversity of insects and flowering plants (Fig. 7; Tab. 3). The abundance of Apis mellifera and solitary bees showed no significant correlations with any plant measure, whereas the abundance of Bombus spp. $(P$ $<0.05)$ and syrphids $(P<0.1)$ were moderately correlated with floral diversity $(H)$. The abundance of butterflies was negatively correlated with floral species richness (S) (Fig. 7; Tab. 3). The number of 
insect groups present $(S)$ and insect diversity $(H)$ were not correlated with any measure of flower abundance or diversity (Tab. 3).

A Mantel test based on rank correlations of the similarity matrices used for the NMDS indicated a weak, although statistically significant, positive relationship between the patterns seen in the insect and floral assemblages seen in the field margins of the different crops over time $(r S=0.133, P<0.025)$.

\section{DISCUSSION}

In the context of our study set in the grassbased Irish agricultural landscape, these results demonstrate that pollinating insects are relatively abundant in field margins even when these margins enclose an in-flower mass-flowering crop, but also highlight that this pattern is highly taxon specific. In particular, honey and bumble bees were more abundant in the crop during its flowering period, but hover flies and butterflies were more prevalent in the boundaries. This could be because social bees can fly relatively long distances to visit mass-flowering resources (Osborne et al. 2007), and because of the other resources offered by boundaries for other insects (e.g. mating and oviposition sites, and larval microhabitats) (Power \& Stout 2011). The assemblage of field margin pollinating insects shifted in time relative to the crop flowering period, a pattern also shown by the assemblage of field margin flowering plants, although there were no general relationships between insect abundance and diversity with the quantity and diversity of flowers available.

In an Irish landscape dominated by improved grassland, field margins and hedgerows might be expected to provide refuge, food and larval resources for various groups of pollinating insects (Power \& Stout 2011; Volpato et al. 2020). Indeed, Stanley \& Stout (2013) reported that all pollinating insect groups were more abundant in field margins compared to the crop centre for a range of crops. However, when mass-flowering crops such as OSR are in bloom, this pattern can change. For example, Walther-Hellwig \& Frankl (2000) found there were more Bombus in OSR than in the hedgerows or field boundaries. During the main crop flowering period, we found no evidence that any insect group was more abundant in the centre of the OSR crop compared with the field margins, but that, in turn, only some groups, such as butterflies and syrphids, showed a distinct preference for field margins. During the flowering period for both apples and OSR, adult butterflies and syrphids are not entirely driven by requirements for pollen and nectar, and the wild plant species present in the field margins offer resources for both adults and their offspring, for example host plants for lepidopteran larvae and prey and for aphidiphagous syrphids (Potts et al. 2009; Stanley $\&$ Stout 2013). The occurrence of honey bees and solitary bees in both the centre and margins of the OSR crop suggest these different habitats offer alternative and/ or complementary resources, and it is known that many wild flowers share pollinating insect species with OSR (Zurbuchen et al. 2010; Jauker et al. 2012; Stanley \& Stout 2014; Coudrain et al. 2016).

Although it has been shown that Bombus colonies do not perform well in a landscape dominated by apple orchards (Proesmans et al. 2019), our results indicated that Bombus showed a preference to forage on apple blossoms compared with adjacent field margins during Period 1 (AprilMay). This pattern may have been accentuated by the presence of managed $B$. terrestris colonies on site, and thus larger number of individuals, during the apple flowering period, but was also observed in non-commercial species (20 individuals in the centre of the crops and 12 in the field margin). The syrphids and butterflies showed a general preference for the field margins over the main crop in all three study periods, and, because A. mellifera and solitary bees were recorded primarily in the field margins after flowering had ceased, insect diversity and richness were, as a consequence, highest in the field margins.

When assessing the field margin insect assemblages in both crops over the three periods, we found taxon specific differences in abundance among study periods but no significant differences between the two crops. Apis mellifera did not show any temporal shift, at least in the field margins, which was unexpected as some beekeepers moved colonies to new sites once flowering ceased. The abundances of solitary bees, hover flies and butterflies all differed among the three study periods, but all three groups exhibited different patterns. These phenological shifts in abundance and/-or activity of adult hover flies and butterflies 

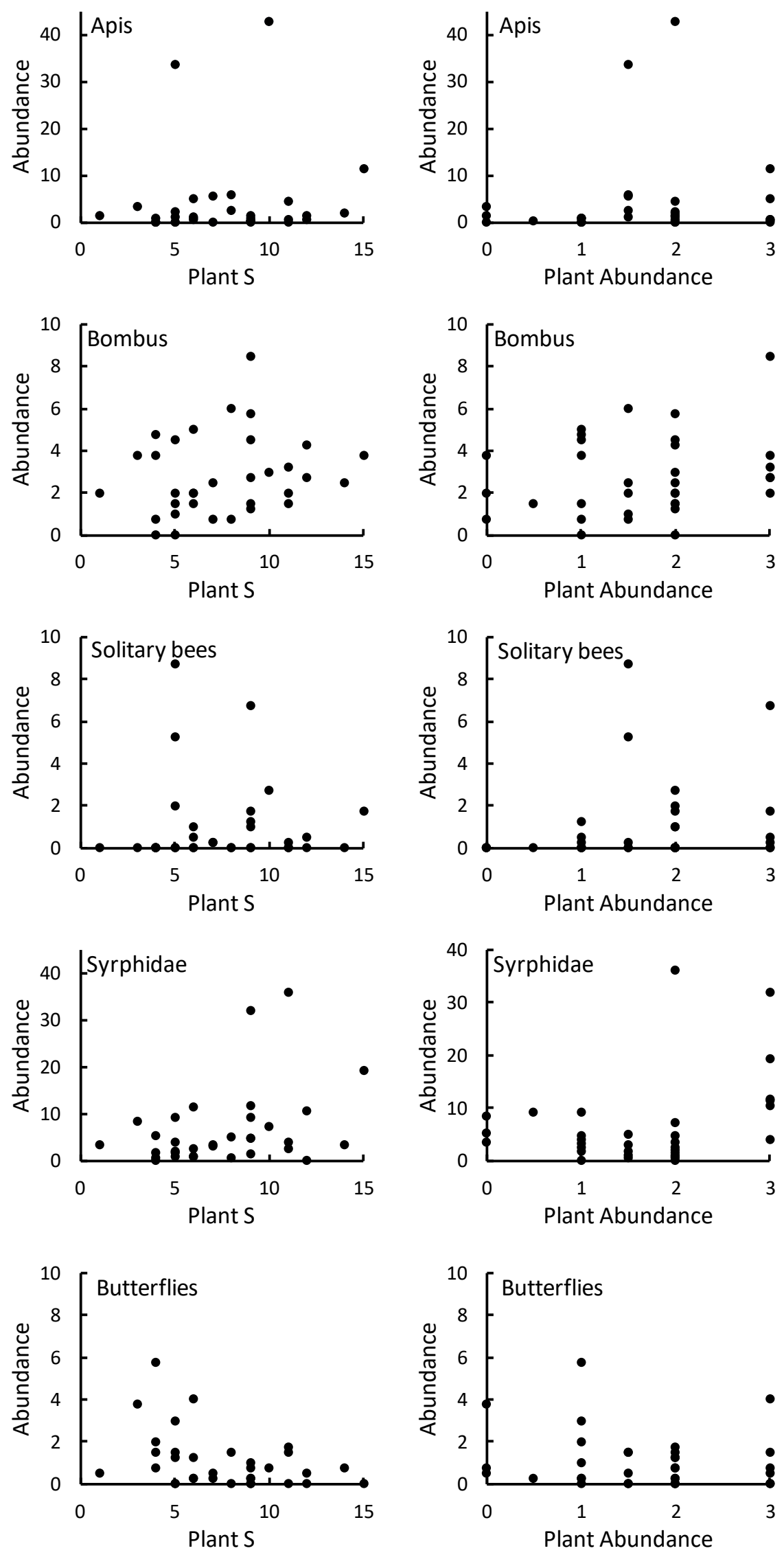

FIGURE 7. Scatterplots illustrating relationships between abundance of pollinating insects (mean counts per $10 \mathrm{~min}$ ) with species richness and abundance (median abundance score) of field boundary flowering plants over three study periods. 
Table 3. Spearman's rank correlation coefficients $\left(r_{s}\right)$ showing strength and direction of relationships between attributes of pollinating insect assemblage and diversity and abundance of flowering plants in field boundaries during 3 site visits. [Critical values of $r_{s}$ with $n=33, P<0.05|0.356|^{* *}$ and $\left.P<0.1|0.301|^{*}\right]$.

\begin{tabular}{|c|c|c|c|c|}
\hline & & \multicolumn{3}{|l|}{ Floral variables } \\
\hline & & Median abundance score & Flower diversity $\mathrm{H}$ & Flower richness $S$ \\
\hline \multirow{8}{*}{ 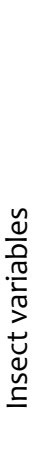 } & Apis mellifera abundance & 0.153 & 0.151 & 0.176 \\
\hline & Bombus abundance & 0.197 & $0.356 * *$ & 0.228 \\
\hline & Solitary bee abundance & 0.292 & 0.184 & 0.197 \\
\hline & Syrphid abundance & 0.196 & $0.337^{*}$ & $0.328^{*}$ \\
\hline & Butterfly abundance & -0.134 & $-0.327^{*}$ & $-0.394^{* *}$ \\
\hline & Total abundance & 0.290 & $0.365^{* *}$ & $0.301 *$ \\
\hline & Insect S & 0.167 & 0.248 & 0.179 \\
\hline & Insect $H$ & 0.057 & -0.002 & -0.027 \\
\hline
\end{tabular}

have been reported previously (Ball \& Morris, 2015; Bond \& Gittings 2008; Cole et al. 2017): many species of butterfly in Ireland are known to exhibit such seasonal 'bimodal' peaks in abundance, resulting from an early population of adults breaking hibernation, followed by a later generation arising from their offspring (Bond \& Gittings 2008).

The changes in relative abundance of the five insect groups among study periods resulted in a temporal shift in the composition of the field margin insect assemblage. There were no differences in the composition of the field margin insect assemblages found on the two crops, possibly because, even when a mass-flowering event occurs, field margins represent a consistent feature occurring through the relatively homogeneous Irish agricultural landscape, and because we only identified insects to functional groups. Seasonal shifts in insect abundance have been reported in several previous studies, and their interactions with naturally-occurring flowering plants will likely change once the numerically-dominant (crop) flowers are no longer present (e.g. Stanley \& Stout 2014; Tiedeken \& Stout 2015; Kovács-Hostyánszki et al. 2019).

The abundance of floral units and diversity of entomophilous flowers in the field margins also varied significantly among study periods, although, as with the insects, there were no differences between the OSR and apple sites. In terms of composition of the floral assemblage, a similar temporal shift was observed as was seen for the insects, although some separation of the floral assemblages occurred between OSR and apples in Period 1, probably because OSR flowered earlier and so sampling Period 1 occurred several weeks earlier than in apples (Appendix I). The results of the Mantel test also indicated that these temporal shifts in the assemblages of entomophilous flowers were associated with parallel temporal shifts in the composition of the insect assemblages, suggesting that the composition and structure of insect-plant interaction networks within each site would also shift with time (Rotenberry 1990; Timberlake et al 2019).

There are many examples of positive relationships occurring between field margin plant diversity/ abundance with the diversity/ abundance of pollinating insects, for example: honey bees (Sanchez et al. 2019), wild bees (Power and Stout 2011; Kovács-Hostyánszki et al. 2019), Bombus (Potts et al. 2009; Purvis et al. 2020), butterflies (Potts et al. 2009; Wix et al. 2019) and syrphids (Sutherland et al. 2001; Cole et al. 2017). In our study, the different pollinator groups exhibited different temporal patterns in abundance, so we felt it was unlikely that we would see any consistent relationships between insect abundance and the abundance and diversity of floral resources in the field margins: fittingly, the correlations we observed were generally weak. This finding may represent a true situation when pollinator metrics are correlated with floral components over time, although the lack of statistically-significant relationships may have 
also reflected numerous methodological aspects of our study: the coarse measures of abundance we used for floral units, the pooling of insects into higher taxonomic groups, some spurious high counts of insects, and the prevalence of zero counts for some taxa in some periods. We did identify positive correlations between floral diversity and Bombus abundance and the total abundance of pollinating insects, which is in general agreement with the studies given above. The lack of relationship between the numbers of syrphids and floral abundance and diversity is similar to that reported by Power \& Stout (2011), and so is at least consistent in the context of Irish field margin insects set in pasture-based agriculture.

We acknowledge that our results were obtained from only a single growing season, and that the sample size, in terms of study sites, offered low statistical power for the detection of weak effects. Additionally, spatial or temporal patterns that may occur for individual species may have been lost by pooling our insect records into higher taxonomic groups, and we have not considered variation in field boundary type within and between study sites. If practicable, future studies would likely benefit from achieving species-level identifications to gain more detailed insight into the autecology of individual pollinator species, and also by examining the robustness of any habitat or temporal responses by assessing their repeatability over multiple growing seasons.

Nonetheless, the data we obtained enabled us to address the original aims of the study, and confirm that hedgerows and field margins, even when they border a flowering crop, represent an important habitat for major pollinating insect groups.

Our findings therefore add additional impetus to the adoption of agri-environment schemes where the protection and improvement of field margins is used as a means of retaining and/ or enhancing farmland biodiversity. Although the composition of the field margin pollinating insect assemblage shifted in time, parallel to changes in the floral assemblage, in our system, insect abundance and diversity were not strongly related to floral abundance and diversity, at least at the physical scale of our study and using our abundance and diversity metrics. Thus, any assessment or scoring of sites based on field margin biodiversity should consider seasonal changes in insect and plant abundance and be conscious that indicators or indices of farmland biodiversity or conservation success based on pollinating insects may not always be correlated with similar indices based on flowering plants.

\section{ACKNOWLEDGEMENTS}

This project received funding from the European Horizon 2020 research and innovation program under grant agreement no.773921. We acknowledge input from Simon Potts, Oliver Schweiger, Alex Klein, Maj Rundlöf, Matthias Albrecht and Mark Brown in developing surveying and site-selection protocols, and thank Christophe Dominik for data on composition of landscape surrounding sampling sites. We thank Amy Turner, Elena Zioga, Sarah Gabel, Muireann Cotter, Margareta Kluth and Teresa Rigoletti for help with field work, and Paul Dowding for his valuable assistance with plant identification. A special acknowledgement is expressed to the farmers who made us welcome and allowed us access to their crops.

\section{APPENDICES}

Additional supporting information may be found in the online version of this article:

Appendix I. Summary of study sites information

Appendix II. Species list of butterflies and bumble bees

Appendix III. Species list of field margin flora

\section{REFERENCES}

Baldock KCR, Goddard MA, Hicks DM, et al (2015) Where is the UK's pollinator biodiversity? The importance of urban areas for flower-visiting insects. The Royal Society. Proceedings of the Royal Society B Biological Sciences 282: 20142849.

Ball S \& Morris R (2015) Britain's Hoverflies: A Field Guide, Revised and Updated Second Edition (WILDGuides), Princeton, New Jersey.

Bond K, Gittings T (2008) Database of Irish Lepidoptera. 1. Macrohabitats, microsites and traits of Noctuidae and butterflies. Irish Wildlife Manuals, No. 35 National Parks and Wildlife Service, Department of the Environment, Heritage and Local Government, Dublin, Ireland.

Campbell AJ, Wilby A, Sutton P, Wäckers FL (2017) Do sown flower strips boost wild pollinator abundance and pollination services in a spring-flowering crop? A case study from UK cider apple orchards. Agriculture, Ecosystems and Environment 239:20-29.

Carolan JC, Murray TE, Fitzpatrick Ú, Crossley J, Schmidt H, Cederberg B, et al. (2012) Colour Patterns 
Do Not Diagnose Species: Quantitative Evaluation of a DNA Barcoded Cryptic Bumblebee Complex. PLoS ONE 7(1): e29251. [online] URL: https://doi.org/10.1371/journal.pone.0029251

Clarke KR (1993) Non-parametric multivariate analyses of changes in community structure. Australian Journal of Ecology 18:117-143.

Cole LJ, Brocklehurst S, Robertson D, et al (2017) Exploring the interactions between resource availability and the utilisation of semi-natural habitats by insect pollinators in an intensive agricultural landscape. Agriculture, Ecosystems and Environment 246:157-167.

Coudrain V, Rittiner S, Herzog F, et al (2016) Landscape distribution of food and nesting sites affect larval diet and nest size, but not abundance of Osmia bicornis. Insect Science 23:746-753.

Curtis K, Bowie MH, Hodge S (2019) Can native plantings encourage native and beneficial invertebrates on Canterbury dairy farms? New Zealand Entomologist 42:67-78.

Day, MC (1991) Towards the conservation of aculeate Hymenoptera in Europe: an outline of the case for recognition of the high value of Hymenoptera Aculeata as indicators of biotype integrity and diversity, with relevant examples and proposals for conservation actions. Nature and Environment Series no. 45. Council of Europe, Strasbourg.

Dicks L V, Corbet SA, Pywell RF (2002) Compartmentalization in plant-insect flower visitor webs. Journal of Animal Ecology 71:32-43.

FAO Food and Agriculture Organisation (2018) fao.org/faostat 2018 data.[online] URL:http://www.fao.org/

Fossitt J (2000) A Guide to Habitats in Ireland. The Heritage Council, Kilkenny, Ireland.

Gathmann A, Tscharntke T (2002) Foraging ranges of solitary bees. Journal of Animal Ecology 71:757-764.

Ghazoul J (2005) Buzziness as usual? Questioning the global pollination crisis. Trends in Ecology and Evolution 20 7:367-373.

Goulson D, Lye GC, Darvill B (2008) Decline and conservation of bumble bees. The Annual Review of Entomology 53:191-208.

Haaland C, Naisbit RE, Bersier L-F (2011) Sown wildflower strips for insect conservation: a review. Insect Conservation and Diversity 4:60-80.

Hass AL, Kormann UG, Tscharntke T, et al (2018) Landscape configurational heterogeneity by smallscale agriculture, not crop diversity, maintains pollinators and plant reproduction in western Europe. The Royal Society. Proceedings of the Royal Society B Biological Sciences 285: 20172242.
Heller S, Joshi NK, Leslie T, et al (2019) Diversified floral resource plantings support bee communities after apple bloom in commercial orchards. Scientific Reports 9:17232.

Henderson P \& Seaby R (2008). A Practical Handbook for Multivariate Methods. January 2008. Pisces Conservation Ltd, Great Britain.

IPBES (2016). The assessment report of the Intergovernmental Science-Policy Platform on Biodiversity and Ecosystem Services on pollinators, pollination and food production. Potts SG, ImperatrizFonseca VL, and Ngo HT (eds) Bonn, Germany.

Jauker F, Peter F, Wolters V, Diekötter T (2012) Early reproductive benefits of mass-flowering crops to the solitary bee Osmia rufa outbalance post-flowering disadvantages. Basic and Applied Ecology 13:268-276.

Kovács-Hostyánszki A, Batáry P, Báldi A (2011) Local and landscape effects on bee communities of Hungarian winter cereal fields. Agricultural and Forest Entomology 13:59-66.

Kovács-Hostyánszki A, Földesi R, Báldi A, et al (2019) The vulnerability of plant-pollinator communities to honeybee decline: A comparative network analysis in different habitat types. Ecological Indicators 97:35-50.

Larkin J, Sheridan H, Finn JA, et al (2019) Semi-natural habitats and Ecological Focus Areas on cereal, beef and dairy farms in Ireland. Land use policy 88:104096.

Le Féon V, Schermann-Legionnet A, Delettre YR, et al (2010) Intensification of agriculture, landscape composition and wild bee communities: A large scale study in four European countries. Agriculture, Ecosystems and Environment 137:143-150.

Marshall EJP, Moonen AC (2002) Field margins in northern Europe: their functions and interactions with agriculture. Agriculture, Ecosystems and Environment 89:5-21.

O'Toole C. (1994). Who cares for the solitary bees? In: A. Matheson (ed) Forage for bee in an agricultural landscape. International Bee Research Association, Cardiff, UK: pp 47-56.

Ollerton J, Winfree R, \& Tarrant S (2011) How many flowering plants are pollinated by animals? Oikos 120(3), 321-326.

Osborne JL, Martin AP, Carreck NL, et al (2007) Bumblebee flight distances in relation to the forage landscape. Journal of Animal Ecology 77: 406-415.

Papanikolaou AD, Kühn I, Frenzel M, Schweiger O (2017) Semi-natural habitats mitigate the effects of temperature rise on wild bees. Journal of Applied Ecology 54:527-536.

Perrot T, Gaba S, Roncoroni M, et al (2018) Bees increase oilseed rape yield under real field conditions. Agriculture, Ecosystems and Environment 266:39-48. 
Plantureux S, Peeters A, McCracken DI (2005) Biodiversity in intensive grasslands: effect of management, improvement and challenges. Agronomy Research 3:153-164.

Potts SG, Woodcock BA, Roberts SPM, et al (2009) Enhancing pollinator biodiversity in intensive grasslands. Journal of Applied Ecology 46:369-379.

Power EF, Stout JC (2011) Organic dairy farming: impacts on insect-flower interaction networks and pollination. Journal of Applied Ecology 48:561-569.

Proesmans W, Smagghe G, Meeus I, et al (2019) The effect of mass-flowering orchards and semi-natural habitat on bumblebee colony performance. Landscape Ecology 34:1033-1044.

Purvis EEN, Meehan ML, Lindo Z (2020) Agricultural field margins provide food and nesting resources to bumble bees (Bombus spp., Hymenoptera: Apidae) in Southwestern Ontario, Canada. Insect Conservation and Diversity 13:219-228.

Rotenberry JT (1990) Variable floral phenology: temporal resource heterogeneity and its implication for flower visitors. Holartic Ecology 13:1-10.

Sanchez JA, Carrasco A, La Spina M, et al (2019) How bees respond differently to field margins of shrubby and herbaceous plants in intensive agricultural crops of the Mediterranean area. Insects 11, 26:1-20.

Scheper J, Holzschuh A, Kuussaari M, et al (2013) Environmental factors driving the effectiveness of European agri-environmental measures in mitigating pollinator loss - a meta-analysis. Ecology Letters 16:912-920.

Sheridan H, McMahon BJ, Carnus T, et al (2011) Pastoral farmland habitat diversity in south-east Ireland. Agriculture, Ecosystems and Environment 144:130135.

Stanley DA, Gunning D, Stout JC (2013) Pollinators and pollination of oilseed rape crops (Brassica napus L.) in Ireland: Ecological and economic incentives for pollinator conservation. Journal of Insect Conservation 17:1181-1189

Stanley DA, Knight ME, Stout JC (2013) Ecological variation in response to mass-flowering oilseed rape and surrounding landscape composition by members of a cryptic bumblebee complex. PLoS One 8(6): e65516. [online] URL: http://doi:10.1371/journal.pone.0065516

Stanley DA, Stout JC (2014) Pollinator sharing between mass-flowering oilseed rape and co-flowering wild plants: implications for wild plant pollination. Plant Ecology 215:315-325.

Stanley DA, Stout JC (2013) Quantifying the impacts of bioenergy crops on pollinating insect abundance and diversity: a field-scale evaluation reveals taxon-specific responses. Journal of Applied Ecology 50:335-344.

Sutherland JP, Sullivan MS, Poppy GM (2001) Distribution and abundance of aphidophagous hoverflies (Diptera: Syrphidae) in wildflower patches and field margin habitats. Agricultural and Forest Entomology 3:57-64.

Tiedeken EJ, Stout JC (2015) Insect-flower interaction network structure is resilient to a temporary pulse of floral resources from invasive Rhododendron ponticum. PLoS One 10:1-19. [online] URL: https://doi.org/10.1371/journal.pone.0119733

Timberlake TP, Vaughan IP, Memmott J (2019) Phenology of farmland floral resources reveals seasonal gaps in nectar availability for bumblebees. Journal of Applied Ecology 56:1585-1596.

The Heritage Council (2010). Proposals for Ireland's landscapes. The Heritage Council, Reeners R, Dublin, pp. 80.

Volpato A, Ahmed KSD, Williams CD, et al (2020) Using Malaise traps to assess aculeate Hymenoptera associated with farmland linear habitats across a range of farming intensities. Insect Conservation and Diversity 13:229-238.

Walther-Hellwig K, Frankl R (2000) Foraging distances of Bombus muscorum, Bombus lapidarius, and Bombus terrestris (Hymenoptera, Apidae). Journal of Insect Behavior 13:239-246.

Winfree R, Aguilar R, Vázquez DP, et al (2009) A metaanalysis of bees' responses to anthropogenic disturbance. Ecology 90:2068-2076.

Wix N, Reich M, Schaarschmidt F (2019) Butterfly richness and abundance in flower strips and field margins: the role of local habitat quality and landscape context. Heliyon 5:e01636.

Wratten SD (1988) The role of field boundaries as reservoirs of beneficial insects. In: Park JR (Ed.), Environmental Management in Agriculture: European Perspectives. Belhaven Press, London, pp. 144-150.

Zurbuchen A, Cheesman S, Klaiber J, et al (2010) Long foraging distances impose high costs on offspring production in solitary bees. Journal of Animal Ecology 79:674-681. 